\title{
The Premature Mortality Cost of Cancers Attributable to Secondhand Smoking in Indonesia
}

\author{
Susi Ari Kristina ${ }^{1}$, Ni Putu Ayu Linda Permitasari², Abdillah Ahsan ${ }^{3}$
}

${ }^{1}$ Department of Pharmaceutics, Faculty of Pharmacy, Universitas Gadjah Mada, Yogyakarta, Indonesia. ${ }^{2}$ Research Assistant, Faculty of Pharmacy, Universitas Gadjah Mada, Yogyakarta, Indonesia. ${ }^{3}$ Faculty of Economics and Business, Universitas Indonesia, Jakarta, Indonesia.

\begin{abstract}
Objectives: Many studies reported that secondhand smoke associated with many health problems including multiple types of cancer. Both secondhand smoking and cancer have a significant economic impact on society, especially in developing countries. To assess this economic burden, we estimated the costs of lost productivity due to premature mortality cancer attributable to secondhand smoking in Indonesia. Methods: This study used to estimate the number of premature mortality cost (PMC) of six cancers (lung, bladder, colorectal, stomach, pancreas and larynx) due to secondhand smoking in Indonesia. This research was using descriptive epidemiological prevalence-based research design, with cancers mortality data gained from Indonesian National Health Insurance (NHI) database in 2016. Results: Burden priorities for Indonesian men and women accounted for IDR 1,075 trillion by lung cancer, IDR 667 trillion by colorectal cancer and IDR 336 trillion by pancreas cancer out of total PMC IDR 2,665 trillion. We also calculated present value for total PMC which was IDR 2,512 trillion after discounted by $3 \%$. The higher premature mortality cost in males than females reflects higher wages and rates of workforce participation. Conclusion: Lost productivity costs due to cancers related to secondhand smoking premature mortality were significant source of high economic burden in Indonesia. The result of this study may provide an alternative perspective on the cancer burden on society and to strengthen tobacco and smoke-free control policy decisions.
\end{abstract}

Keywords: Burden of disease- secondhand smoke- cancer- premature mortality cost- Indonesia

Asian Pac J Cancer Care, 4 (4), 107-112

\section{Introduction}

Secondhand smoke has been a big problem for human being worldwide as it is well-established as risk factors for many diseases. Many studies have reported that exposure to secondhand smoke can cause various diseases such as coronary heart disease, stroke, respiratory disorders in adults, and infant death syndrome in infants and children [1], also several types of cancers indicated by relative risk value of more than one [2].

There are 4000 harmful chemical compounds contained in cigarette smoke, including nicotine, tar, cyanide, benzene, cadmium, methanol, ammonia, and arsenic [2]. The amount of harmful substances in the body of secondhand smokers is greater than active smokers because the toxins inhaled through the breath are not filtered; make them more susceptible to health
Submission Date: 04/07/2019 Acceptance Date: 07/03/2019

problems compared to active smokers (REF).

Although the prevalence of smoker among women is relatively low, women and children still have health risks as secondhand smokers due to men smoking at home or elsewhere. In addition, the 2001 Indonesia National Socio-Economic Survey in Reimondos et al (2012) estimates that nearly $50 \%$ of the total population is affected by secondhand smoking caused by family members who smoke indoors [3].

Moreover, secondhand smoke is a major problem in countries of the Asia region as a large portion of the population smokes tobacco and the level of general awareness about the actual harmful effects of secondhand smoke is still not sufficient. Indonesia as one of nation with high population of smokers in Asia resulted in higher risk of people exposed to or inhaling cigarette smoke as secondhand smokers.

\section{Corresponding Author:}

Dr. Susi Ari Kristina

Department of Pharmaceutics, Faculty of Pharmacy, Universitas Gadjah Mada, Yogyakarta, Indonesia.

Email: susiari_k@ugm.ac.id 
Furthermore, like other places in the world cancer is an increasing problem in Indonesia as cancer is currently the leading cause of death in economically developed countries [4]. While advances in diagnosis and treatment over the past decades have resulted in improved survival rates in developed countries, future growth in new cancer cases is projected due to population growth and aging [5]. It was recently estimated that there were over 700,000 new cases of cancer and 500,000 cancer deaths in Southeast Asia region in the year 2008. Recent study indicated that over $75 \%$ of cancer patients in Asia experiencing death or financial catastrophe within one year [6]. Furthermore, these numbers were expected to increase, leading to substantial need for effective cancer control intervention and cancer service provision [7].

According to global burden of disease (GBD) calculation, secondhand smoking contributed 9,316,121 DALYs globally in 2013 [2] and more than 0.6 million premature deaths occur due to non-smokers who becoming passive smokers [1]. Cancer due to secondhand smoking also has an economic impact on society. One important element of this economic impact is the cost of lost productivity due to premature mortality.

There is currently no research which specifically measuring the burden of cancer due to secondhand smoking in Indonesia using premature mortality cost (PMC) indicator as also it is very limited number of studies of productivity loss in multiple cancer sites exist. This study was performed to estimate the burden of cancers attributable to secondhand smoking using PMC indicator in Indonesia. The data obtained can be used as alternative perspective and contribute in policy making in the context of prevention and control of tobacco and cigarettes through health promotion to raise public awareness about the negative impact of tobacco smoke, in term of the economic burden of the country.

\section{Materials and Methods}

This research was using descriptive epidemiological prevalence-based research design to estimate the burden of cancers due to secondhand smoking in Indonesian population. There were four steps to gain the data; first, we selected the secondhand smoke-related cancers in Indonesia from systematic review studies. Second, we find out the average life expectancy per age group of Indonesian population both in male and female. Third, we find out the average income of Indonesian population both in male and female. The last, we calculated the premature mortality cost of cancers related to secondhand smoking in Indonesia.

\section{Selection of secondhand smoke-related cancers}

The selection of secondhand smoke-related cancers included in this study was based on a systematic review. According to the levels of evidence, we decided to include 6 secondhand smoke-related cancer diseases (lung, bladder, colorectal, stomach, pancreas and larynx) from Kristina et al., 2018 study [8]. From that study, the relative risks for those cancers were obtained from monograph of meta-analysis by International Agency for Research on Cancers (IARC) [2]. Meanwhile, the prevalence of secondhand smoking was obtained from Global Adult Tobacco Survey: Indonesian Report 2011 which reported by World Health Organization Regional Office for South East Asia and Health Minister of Indonesia [8]. The study also already mention the estimation of secondhand smoke attributable fraction (SAF) of 6 cancers both in male and female that needed to the calculation of this study.

\section{The average income of Indonesian population}

The average income of Indonesian population was obtained from Indonesian Central Bureau of Statistics, data in August 2016 [9]. The average monthly income of 2016 in men was IDR 2,755,374 while in women IDR $2,192,723$. Those average monthly income were multiplied by 12 (number of months in one year), so that the average income of the community is obtained in a year because there is no specific data on average community income per year in different gender.

\section{Calculation of premature mortality cost}

To estimate the premature mortality cost (PMC), first, we estimated the number of mortality of cancers by gender gained from Indonesian national health assurance system 2016. The mortality of some types of cancer in age group both male and female in Indonesia is shown in Table 1.

Second, to estimate the cancer mortality attributable to secondhand smoking, the value of SAF multiplied with mortality number of specific cancer in male and female per age group. Third, we calculated the PMC by multiplying cancer mortality attributable to secondhand smoking by standard expected years of life in 2015 to calculate the years of premature death [2].

The life expectancy used in this study was adjusted to the availability of data on the age range of cancer mortality in GLOBOCAN 2012. The life expectancy used in this study was the median of life expectancy in the age range 15 - 59 years. Life expectancy in the age group 0 - 14 years and over 60 years was excluded because it does not include in productive age which between 15 - 59 years. In this study, we used life expectancy data in 2012 because it is the available year closest to the year of research.

Life expectancy used was the median of life expectancy in the range of age 15 - 39 years (45.4 years for male and 48.9 years for female), life expectancy age 40 - 44 years (31.7 for male and 35 for female), ages 45 - 49 years (27.2 for male and 30.5 for female), range 50 - 54 (23 for male and 26.2 for female), ages 55 - 59 (19 for male and 22 for female) ages 60 to 64 (15.4 for male and 17.9 for female). Details of the life expectancy data can be seen in Table 2 .

The last, the calculation result then multiplied by the average income of Indonesian population in 2016 to get the premature mortality cost. The diagram of this study steps is shown in Figure 1.

\section{Results}

Secondhand smoking is attributable to about $80.20 \%$ of 
Table 1. Cancer Mortality Rate in Indonesia, 2016

\begin{tabular}{|c|c|c|c|c|c|c|}
\hline \multirow[t]{2}{*}{ Age range } & \multicolumn{6}{|c|}{ Type of the cancer } \\
\hline & Lung & Colorectal & Larynx & Pancreas & Stomach & Bladder \\
\hline \multicolumn{7}{|l|}{ Male } \\
\hline $15-39$ & 60 & 116 & 7 & 20 & 14 & 124 \\
\hline $40-44$ & 172 & 115 & 7 & 28 & 11 & 26 \\
\hline $45-49$ & 405 & 176 & 36 & 56 & 19 & 132 \\
\hline $50-54$ & 676 & 284 & 59 & 96 & 24 & 128 \\
\hline Total & 2,237 & 1,093 & 184 & 323 & 102 & 561 \\
\hline \multicolumn{7}{|l|}{ Female } \\
\hline $15-39$ & 86 & 129 & 9 & 16 & 21 & 38 \\
\hline $40-44$ & 138 & 104 & 3 & 13 & 16 & 17 \\
\hline $45-49$ & 273 & 170 & 4 & 39 & 36 & 38 \\
\hline $50-54$ & 418 & 244 & 12 & 67 & 49 & 48 \\
\hline $55-59$ & 488 & 296 & 14 & 90 & 50 & 70 \\
\hline Total & 1,403 & 943 & 42 & 225 & 172 & 211 \\
\hline Total & 3,640 & 2,036 & 226 & 548 & 274 & 772 \\
\hline
\end{tabular}

pancreas cancers in Indonesian men while accounted for approximately $78.95 \%$ in Indonesian female. Comparing the cancers, for male, SAF were the highest in pancreas cancer while the second and third ranks were identified in stomach cancer and larynx cancer, $79.54 \%$ and $60.61 \%$ respectively. Different pattern was found in female, SAF was the highest in pancreas cancer $(78.95 \%)$ while the second and third highest was found in stomach and bladder cancer, $78.26 \%$ and $63.30 \%$ respectively [8]. (Table 3).

Cancer mortality due to secondhand smoking is displayed by cancer types in Table 4 . Total number of cancer death related to secondhand smoking in Indonesia

Table 2. Life Expectancy Per Age Groups both in Male and Female

\begin{tabular}{lcc}
\hline $\begin{array}{l}\text { Age groups } \\
\text { (years) }\end{array}$ & \multicolumn{2}{c}{ Life expectancy } \\
\hline$<1$ & Male & Female \\
$1-4$ & 67.1 & 71.2 \\
$5-9$ & 67.9 & 71.7 \\
$10-14$ & 64.2 & 68 \\
$15-19$ & 59.4 & 63.2 \\
$20-24$ & 54.6 & 58.3 \\
$25-29$ & 49.9 & 53.6 \\
$30-34$ & 45.4 & 48.9 \\
$35-39$ & 40.8 & 44.2 \\
$40-44$ & 36.2 & 39.6 \\
$45-49$ & 31.7 & 35 \\
$50-54$ & 27.2 & 30,5 \\
$55-59$ & 23 & 26.2 \\
$60-64$ & 19 & 22 \\
$65-69$ & 15.4 & 17.9 \\
$70-74$ & 12.2 & 14.3 \\
\hline
\end{tabular}

Source: WHO Life Tables, 2015 in 2016 was 3,354 cases $(2,263$ in male and 1,091 in female). The highest deaths of cancers due to secondhand smoking for age 15 - 59 population in Indonesia were attributed by lung cancer $(1,404)$, colorectal $(816)$ and pancreas (437). Meanwhile the number of cancer deaths among male, the three highest were lung cancer $(1,139)$, colorectal cancer (461) and pancreas (259). Meanwhile, the numbers of cancer deaths due to secondhand smoking in female, the three highest were colorectal cancer (355), lung (265) and pancreas (178) respectively.

When looking at the premature mortality cost (PMC) calculation result, it was found that secondhand smoking accounted for IDR 1,074,893,012,201 of lung cancer, IDR $666,901,166,788$ of colorectal cancer and IDR 336,752,883,199.00 of pancreas cancer out of total PMC IDR 2,665,245,707,700. The three highest PMC of cancer attributable to secondhand smoking for male in Indonesia was caused by lung, colorectal and pancreas cancer respectively. Different from male, in female the three highest PMC was caused by colorectal, lung and pancreas cancer as shown in Table 5.

Furthermore, Figure 2 is presented to show the ratio of PMCs of cancer due to secondhand smoking in both male and female in Indonesia. The results show that PMC between the genders varies with each other depending on the type of cancer. PMC higher values in males appear

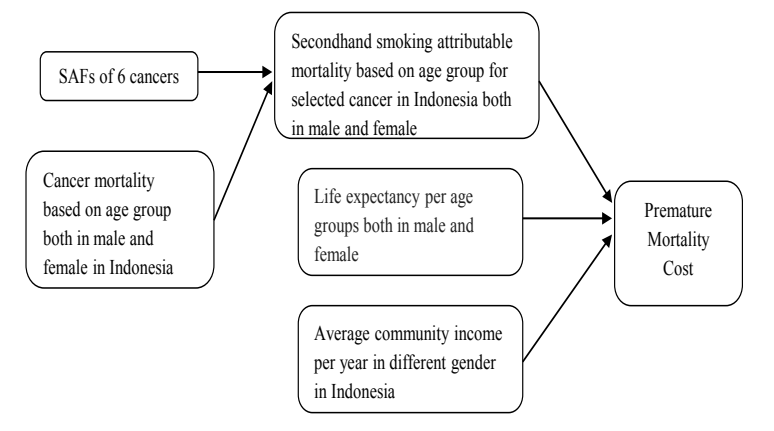

Figure 1. The Study Steps 
Tabel 3. Relative Risks and SAFs Due to Secondhand Smoking for Selected Cancers in Indonesia (Kristina et al., 2018)

\begin{tabular}{lcccc}
\hline Cancers & \multicolumn{2}{c}{ Relative risks } & \multicolumn{2}{c}{ SAFs (\%) } \\
& Male & Female & Male & Female \\
\hline Lung & 2.28 & 1.31 & 50.90 & 18.86 \\
Colorectal & 1.90 & 1.80 & 42.16 & 37.50 \\
Stomach & 5.80 & 5.80 & 79.54 & 78.26 \\
Bladder & 1.75 & 3.30 & 37.79 & 63.30 \\
Pancreas & 6.00 & 6.00 & 80.20 & 78.95 \\
Larynx & 2.90 & 2.90 & 60.61 & 58.76 \\
\hline
\end{tabular}

only for lung and larynx cancer than in female.

\section{Discussion}

When looking at the PMC cancers attributable to secondhand smoking calculation result, it was found that lung cancer accounted for IDR 1,075 trillion, almost half of out of total PMC IDR 2,665 trillion as of the highest burden of disease related to secondhand smoking. We currently did not found any studies of productivity loss in multiple cancer specify due to secondhand smoking exist which make it hard in comparing our result to the other countries.

There were just studies about PMC of cancer generally, two of them conducted in Australia. In Carter et al (2017) study, the premature deaths occurring in 2003 accounted for about $\$ 13.8$ billion Australian dollars in present value of lifetime income (PVLI) lost when modeled to 2030 [10]. Deaths from cancer and cardiovascular disease accounted for more than half the total PVLI impact of many diseases. Another, premature deaths from cancer in Australia 2003 resulted in cost of $\$ 4.2$ billion Australian dollars. Costs were close to three times higher in males than females due to the higher number of premature

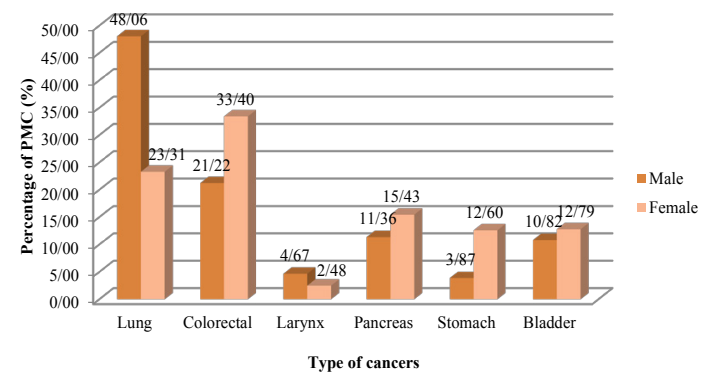

Figure 2. Premature Mortality Costs of Cancers Related to Secondhand Smoking in Indonesia 2016.

deaths in men, combined with higher levels of workforce participation and income. Lung, colorectal and brain cancers accounted for the highest proportion of costs [11]. Meanwhile, our study result shows the PMC of six cancers due to secondhand smoking was close to two times higher in males than females and same as the PMC cancer study in Australia lung and colorectal accounted for the highest proportion of costs. Hence, the economic burden of cancer due to secondhand smoking required consideration of those cancers.

Premature Mortality Cost (PMC) is defined as parameters of the lost income caused by premature mortality based on human capital and obtained by calculating the number of mortality with life expectancy and average income [12]. Translation of the burden of diseases with the parameters PMC is able to provide evidence, so policy makers can understand that ultimately the state will still be harmed because of decreased public productivity and increased health costs to be borne by the government as a result of that risk factors [13].

In another hand, discounting allows calculation of the present value of payments that will be made in the future. Since the present and future currency values are not the same, if the intervention is done within a few years, future

Table 4. Cancer Mortality Attributable to Secondhand Smoking in Indonesia, 2016

\begin{tabular}{|c|c|c|c|c|c|c|c|}
\hline \multirow[t]{2}{*}{ Age range } & \multicolumn{6}{|c|}{ Type of the cancer } & \multirow[t]{2}{*}{ Total } \\
\hline & Lung & Colorectal & Larynx & Pancreas & Stomach & Bladder & \\
\hline \multicolumn{8}{|l|}{ Male } \\
\hline $15-39$ & 31 & 49 & 4 & 16 & 11 & 47 & 158 \\
\hline $40-44$ & 88 & 49 & 4 & 22 & 9 & 10 & 182 \\
\hline $45-49$ & 206 & 74 & 22 & 45 & 15 & 50 & 412 \\
\hline $50-54$ & 344 & 120 & 36 & 77 & 19 & 48 & 644 \\
\hline $55-59$ & 470 & 169 & 45 & 99 & 27 & 57 & 867 \\
\hline Total & 1,139 & 461 & 111 & 259 & 81 & 212 & 2,263 \\
\hline \multicolumn{8}{|l|}{ Female } \\
\hline $15-39$ & 16 & 49 & 6 & 13 & 17 & 24 & 125 \\
\hline $40-44$ & 26 & 39 & 2 & 10 & 12 & 11 & 100 \\
\hline $45-49$ & 52 & 64 & 2 & 31 & 28 & 24 & 201 \\
\hline $50-54$ & 79 & 92 & 7 & 53 & 39 & 30 & 300 \\
\hline $55-59$ & 92 & 111 & 8 & 71 & 39 & 44 & 365 \\
\hline Total & 265 & 355 & 25 & 178 & 135 & 133 & 1,091 \\
\hline Grand Total & 1,404 & 816 & 136 & 437 & 216 & 345 & 3,354 \\
\hline
\end{tabular}


Table 5. Premature Mortality Cost of Cancer Attributable to Secondhand Smoking in Indonesia 2016

\begin{tabular}{lcccc}
\hline No & Type of cancers & \multicolumn{2}{c}{ PMC } & Total \\
& & Male & Female & \\
\hline 1 & Lung & $880,910,702,194$ & $193,982,310,007$ & $1,074,893,012,201$ \\
2 & Colorectal & $388,894,588,510$ & $278,006,578,278$ & $666,901,166,788$ \\
3 & Larynx & $85,630,411,022$ & $20,623,875,449$ & $106,254,286,471$ \\
4 & Pancreas & $208,299,661,502$ & $128,453,221,697$ & $336,752,883,199$ \\
5 & Stomach & $70,847,278,438$ & $104,858,645,128$ & $175,705,923,565$ \\
6 & Bladder & $198,314,186,126$ & $106,424,249,350$ & $304,738,435,476$ \\
Total & & $1,832,896,827,792$ & $832,348,879,908$ & $2,665,245,707,700$ \\
\hline
\end{tabular}

costs should be adjusted (discounting) to reflect its current value. Present Value (PV) can be calculated by multiplying the future cost (Future Cost/FC) with discount factor (DF). DF depends on two variables, which are number of years (n) and discount rate (r) [14].

There is no agreement on the discount rate to be used in the scientific literature. There are significant variations in public discount rate policies practiced by countries around the world, reflect the different analytical approaches followed by various countries in choosing the social discount rate [15]. The general discounted rate used in many studies is $3 \%$. As the average income used came from Indonesian Central Bureau of Statistics, data were in August 2016, the present value of total PMC cancer due to secondhand smoking 2018 is IDR 2,512 trillion.

Summarizing the results, we can state that cancer attributable to secondhand smoking is responsible for a large amount of economic lost due to premature mortality. Therefore, public health interventions should focus on the prevention of smoking as soon as possible, ideally since in young age [16]. Appropriate policies to reduce both home and workplace smokers are also indispensable. To effectively reduce the incidence of secondhand smokers at home, it is necessary to counsel, educate, and advise on the dangers of tobacco smoke and make plans to eliminate the habits, especially in men. Not only the ban or punishment, appreciation may also need to be given to the agency or workplace that is firmly in the smoking ban [17-18].

As far as we are aware, this study provides the first estimates of PMC for multiple cancers due to secondhand smoking for Asian country. Key strengths of the study include the use of population data of Indonesia and the application of a simple and transparent methodology to value lost productivity. Nevertheless, there are some limitations caused by the number of deaths of cancer is not purely from Indonesian database, but the proportion of estimated deaths from GLOBOCAN (2012) and BPJS Health (2016) per age group and gender. The community income used in this study were also not based on age group which not differ the older males/female who was working compared to younger citizens (who earn lower wages). Besides that, the income data at BPS 2016 is the average wage/net salary for a month laborers, whereas for PMC estimation required average quarterly income to gain specific results. Future studies can provide more robust estimation regarding PMC of cancers due to secondhand smoking by pay attention to those factors.
Lost productivity costs in Indonesia due to cancers related to secondhand smoking premature mortality are significant, which reach total IDR 2,512,249,700,914.00 after discounted. The higher premature mortality cost in males than females reflects higher wages and rates of workforce participation. The result of this PMC provides an alternative perspective on the cancer burden on society and may inform cancer and tobacco control policy decisions.

\section{Conflict of interest}

The authors declare there is no conflict of interest.

\section{References}

1. Chen J, Wang MP, Wang X, Viswanath K, Lam TH, Chan SS. Secondhand smoke exposure (SHS) and health-related quality of life (HRQoL) in Chinese never smokers in Hong Kong. BMJ Open. 2017;5:e007694.

2. World Health Organization. International Agency for Research on Cancer Monographs on The Evaluation of Carcinogenic Risks to Humans - Second-Hand Tobacco Smoke Paris: WHO Publications, 2015.

3. Reimondos A, Utomo ID, McDonald P, et al. Greater Jakarta Transition to Adulthood Survey Policy Australia. Sydney: Australian Demographic and Social Research Institute The Australian National University, 2010.

4. Sein AA, Than Htike MM, Sinha DN, Kyaing NN. Exposure to second-hand tobacco smoke among adults in Myanmar. Indian J Cancer. 2012;49:410-8.

5. Hanly PA, Sharp L. The cost of lost productivity due to premature cancer -related mortal i ty: An economic measure of the cancer burden. BMC Cancer 2014;14(224).

6. Kimman M, Jan S, Yip C, Thabrany H, Peters SA, Bhoo-Pathy $\mathrm{N}$, et al. Catastrophic health expenditure and 12-month mortality associated with cancer in Southeast Asia: results from a longitudinal study in eight countries. BMC Med. 2015;13(190).

7. Kimman M, Norman R, Kingston M, Woodward M. The burden of cancer in member countries of the Association of Southeast Asian Nations (ASEAN). Asian Pac J Cancer Prev. 2012;13(2):411-20.

8. Kristina SA, Satibi S, Permitasari NPAL. National Burden of Cancers Atrributable to Secondhand Smoking in Indonesia. Asian Pac J of Cancer Prev. 2018; accepted.

9. National Bureau of Statistics. Keadaan Angkatan Kerja di Indonesia Agustus 2016. Jakarta: National Bureau of Statisctics, 2016.

10. Carter HE, Schofield D, Shrestha R. The long-term productivity impacts of all cause premature mortality in 
Australia. Aust NZ J Public Health. 2017;41:137-43.

11. Carter HE, Schofield DJ, Shrestha R. The Productivity Costs of Premature Mortality Due to Cancer in Australia: Evidence from a Microsimulation Model. PLoS ONE 2016;11(12).

12. Kristina SA, Endarti D, Prabandari YS, Ahsan A, Thavorncharoensap M. Burden of Cancers Related to Smoking among the Indonesian Population: Premature Mortality Costs and Years of Potential Life Lost. Asian Pac J Cancer Prev 2015;16(16):6903-8.

13. Centers for Disease Control and Prevention. State Tobacco Revenues Compared with Tobacco Control Appropriations. MMWR weekly. 2012;61(20):370-74.

14. Hanly P, Soerjomataram I, Sharp L. Measuring the societal burden of cancer: The cost of lost productivity due to premature cancer-related mortality in Europe. Intl J Cancer. 2015;136(4):E136-E45.

15. Zhuang J, Liang Z, Lin T, Guzman FD. Theory and Practice in the Choice of Social Discount Rate for Cost-Benefit Analysis: A Survey. Manila: Asian Development Bank., 2007.

16. Golechha M. Health Promotion Methods for Smoking Prevention and Cessation: A Comprehensive Review of Effectiveness and the Way Forward. Int J Prev Med. 2016;7(7).

17. Hori M, Tanaka H, Wakai K, Sasazuki S, Katanoda K. Secondhand smoke exposure and risk of lung cancer in Japan: a systematic review andmeta-analysis of epidemiologic studies. Jpn J Clin Oncol. 2016;46(10).

18. Zahra A, Cheong HK, Lee EW, Park JH. Burden of Disease Attributable to Secondhand Smoking in Korea. Asia Pac J Pub Health. 2016;1-14.

\section{(c) (i) (8)}

This work is licensed under a Creative Commons AttributionNon Commercial 4.0 International License. 